\title{
Primary malignant melanoma of the spinal cord: a case report
}

\author{
Ashutosh Das Sharma, Jyoti Poddar, Ubrangala Suryanarayan Kunikullaya, Jay Prakash Neema
}

Department of Radiotherapy, Gujarat Cancer and Research Institute, Asarwa 380016, Ahmedabad, India.

Correspondence to: Dr. Ashutosh Das Sharma, Department of Radiotherapy, Gujarat Cancer and Research Institute, Asarwa 380016, Ahmedabad, India.

E-mail: sharmaashutoshdas@gmail.com

\section{A B S T R A C T}

Primary malignant melanoma of the central nervous system is rare, and the events involving the spinal cord are even more infrequent. A 30 -year-old male presented with a mass lesion of the spinal cord. After radiological workup, the mass was resected in December 2012. The histopathological examination report and immunohistochemistry suggested malignant melanoma. PET-CT scan, brain MRI, and funduscopic examination did not reveal malignant melanoma elsewhere in the body. The patient received postoperative radiotherapy until March 2013. Presently, the patient is asymptomatic with normal neurological functions.

Key words: Malignant melanoma; cervical spine; spinal cord; intramedullary; central nervous system

\section{INTRODUCTION}

Primary malignant melanoma of the central nervous system (CNS) is rare, with less than 60 cases reported in the literature $;^{[1]}$ a disease that presents substantial diagnostic, prognostic and therapeutic challenges. We report a case of primary malignant melanoma of the spinal cord which was treated successfully with surgery and adjuvant radiation therapy (RT).

\section{CASE REPORT}

A 30 years old male presented with complaints of pain/ stiffness in the neck and numbness/weakness in all four limbs. The symptoms had been present for 90 days and were gradually progressing.

Magnetic resonance imaging (MRI) scan of the cervical spine [Figures 1 and 2] showed an intradural extramedullary enhancing mass lesion at the second and third cervical vertebral level, compressing the spinal cord with focal cord edema and anterior-right lateral displacement of the spinal cord. The lesion measured $14 \times 17 \times 29 \mathrm{~mm}$ in size and was hyperintense on $\mathrm{T} 1$ and hypointense on T2 weighted images. Another intradural extramedullary mass lesion was found at the craniovertebral level, indenting the cervicomedullary junction. This lesion measured $13 \times 18 \times 16 \mathrm{~mm}$

\begin{tabular}{|l|l|}
\hline \multicolumn{3}{|c|}{ Access this article online } \\
\hline Quick Response Code: & Website: \\
& http://jcmtjournal.com \\
\cline { 2 - 2 } & \\
\hline
\end{tabular}

in size and was hyper to hypointense on T1 and isointense on $\mathrm{T} 2$ weighted images.

The patient underwent laminectomy and surgical excision and decompression on November 26th 2012. No residual lesion was found on postoperative MRI scan.

The histopathological examination showed clusters of atypical spindle cells with prominent nucleoli and eosinophilic cytoplasm [Figure 3], with evident intra- and extracellular pigment deposition. Immunohistochemistry staining showed positivity for HMB-45 [Figure 4], S-100 [Figure 5], and Melan-A [Figure 6]; all consistent with the histopathological diagnosis of malignant melanoma.

A thorough systemic survey was done including PET scan, tumor markers, ophthalmological, and dermatological examinations. These did not reveal any other foci of melanoma, leading to the diagnosis of primary spinal malignant melanoma. The patient received postoperative RT (50 Gray in 25 fractions on a linear accelerator with 6 MV photons by parallel opposed portals) from January 3rd to February 13th 2013. Since then, the patient has been on regular follow up with normal neurological functions.

This is an open access article distributed under the terms of the Creative Commons Attribution-NonCommercial-ShareAlike 3.0 License, which allows others to remix, tweak, and build upon the work non-commercially, as long as the author is credited and the new creations are licensed under the identical terms.

For reprints contact: service@oaepublish.com

How to cite this article: Sharma AD, Poddar J, Kunikullaya US, Neema JP. Primary malignant melanoma of the spinal cord: a case report. J Cancer Metastasis Treat 2016;2:144-6.

Received: 12-08-2015; Accepted: 19-12-2015. 


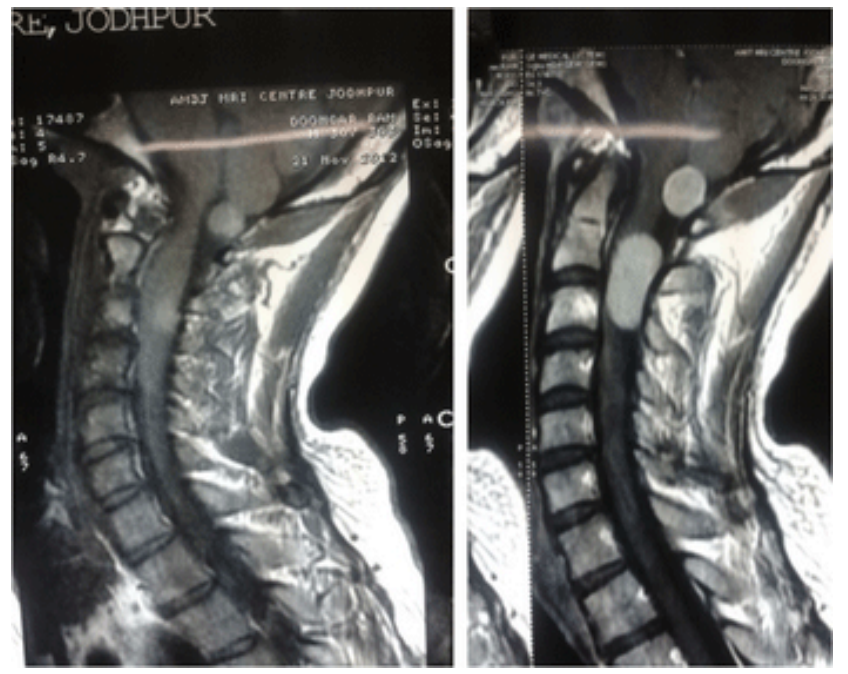

Figure 1: MRI of cervical spine, sagittal plane. MRI: Magnetic resonance imaging

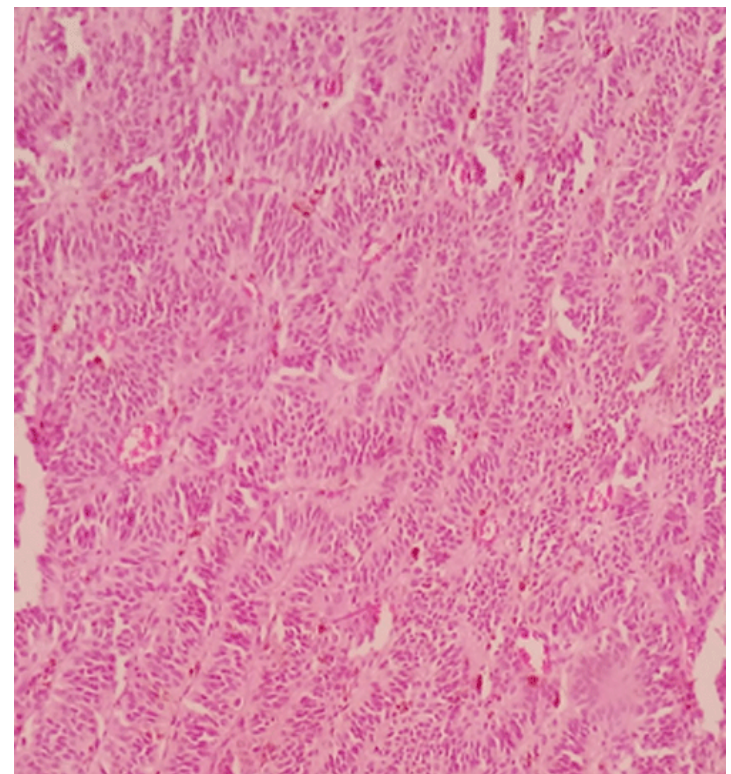

Figure 3: Low power hematoxylin-eosin staining slide $(\times 10)$

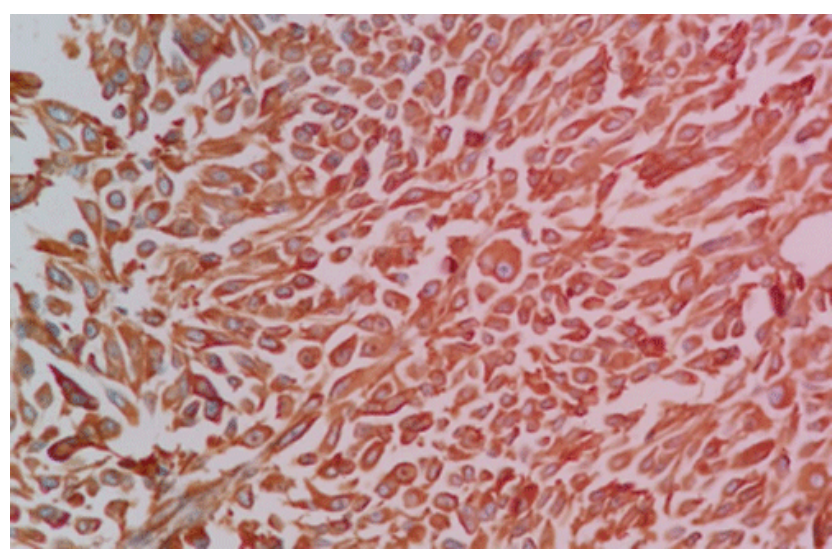

Figure 5: Histopathological slide stained with S-100 (× 40)

\section{DISCUSSION}

Primary malignant melanoma of the CNS is rare. Other

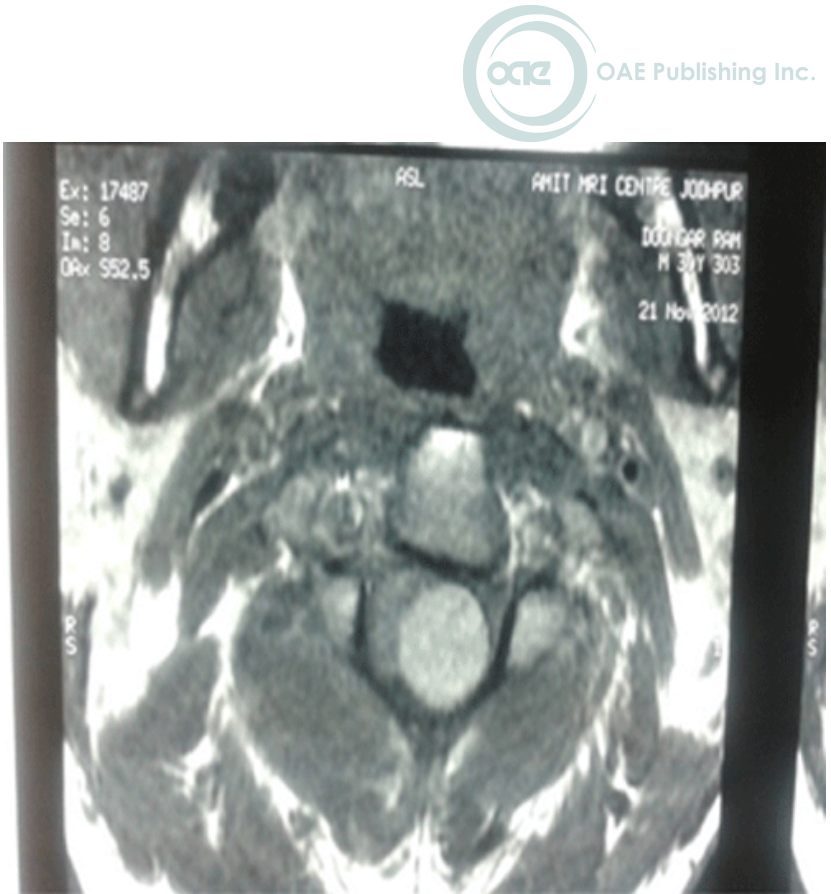

Figure 2: MRI of cervical spine, transverse plane. MRI: Magnetic resonance imaging

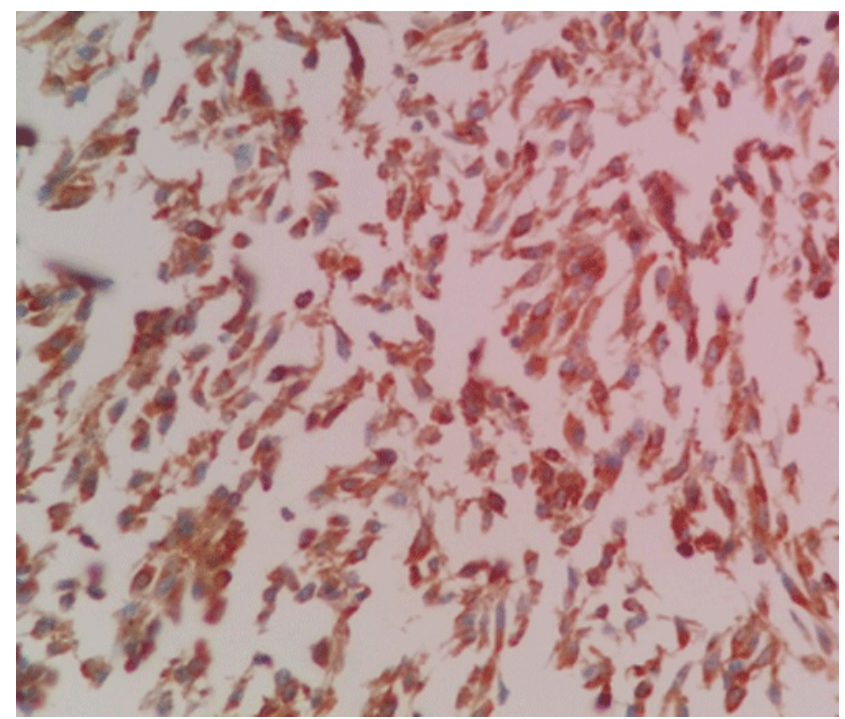

Figure 4: Histopathological slide stained with HMB-45 ( × 40)

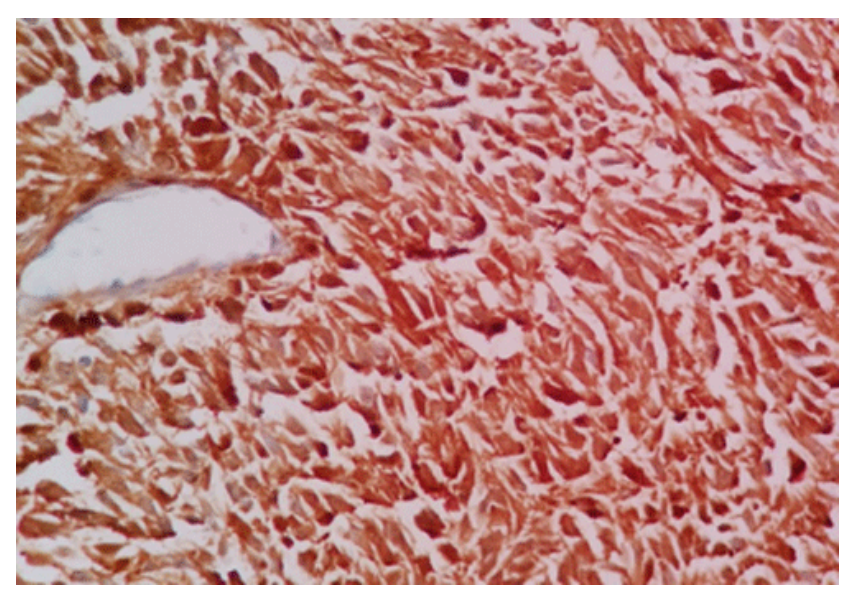

Figure 6: Histopathological slide stained with Melan-A (× 40)

noncutaneous primary malignant melanoma sites include the gastrointestinal tract and the eyes. Primary malignant 
melanoma of the spinal cord most commonly involves the thoracic spine, followed by the cervical spine, and the lumbar region. ${ }^{[2]}$ The diagnosis requires exclusion of a primary cutaneous or ocular lesion, as malignant melanoma, although infrequently, can metastasize to the spinal cord..$^{[3]}$

The melanotic tumors of the CNS should be distinguished from other pigmented CNS lesions, e.g., meningioma, schawnnoma, pigmented astrocytoma, and gliomas. ${ }^{[4]}$ The diagnosis can be confirmed by histology and immunohistochemistry, as per Hayward's criteria stating that "there should be no melanoma outside the CNS, and the confirmation should be done by IHC. ${ }^{[5] " ~ M e l a n o c y t i c ~}$ tumors are positive for S-100, HMB45, and Melan-A.

MRI of spinal cord melanoma shows characteristic features such as high signal intensity on T1-weighted images and equal or low signal intensity on T2-weighted images, ${ }^{[6]}$ due to the paramagnetic properties of melanin or the hemorrhagic elements in the tumor. ${ }^{[6]}$ Currently, there is no standard treatment for primary malignant melanoma of the spinal cord. The treatment regimen is similar to that of metastatic disease in the spinal cord, i.e., surgical resection followed by postoperative RT. Chemo- and immunotherapy have no proven clinical effects. ${ }^{[7]}$ Differentiation between primary and secondary CNS melanoma is important, because primary CNS melanoma is associated with longer overall survival (OS) ${ }^{\left[{ }^{[8,9]}\right.}$ OS in secondary CNS melanoma patients is less than one year, ${ }^{[1]}$ although complete surgical resection followed by postoperative RT does increases OS in these patients. ${ }^{[10]}$ However, lack of conclusive data renders the clinical outcome of spinal cord melanoma unpredictable. ${ }^{[2]}$

\section{Financial support and sponsorship}

Nil.

\section{Conflicts of interest}

There are no conflicts of interest.

\section{REFERENCES}

1. Fuld AD, Speck ME, Harris BT, Simmons NE, Corless CL, Tsongalis GJ, Pastel DA, Hartford AC, Ernstoff MS. Primary melanoma of the spinal cord: a case report, molecular footprint, and review of the literature. J Clin Oncol 2011;29:e499-502.

2. Kim MS, Yoon do H, Shin DA. Primary spinal cord melanoma-case report. J Korean Neurosurg Soc 2010;48:157-61.

3. Hayward RD. Malignant melanoma and the central nervous system: A guide for classification based on the clinical findings. $J$ Neurol Neurosurg Psychiatry 1976;39:526-30.

4. Jaiswal S, Vij M, Tungria A, Jaiswal AK, Srivastava AK, Behari S. Primary melanocytic tumours of the central nervous system: a neuroradiological and clinicopathological study of five cases and brief review of literature. Neurol India 2011;59:413-9.

5. Chamberlain MC, Tredway TL. Adult primary intradural spinal cord tumors: a review. Curr Neurol Neurosci Rep 2011;11:320-8.

6. Farrokh D, Fransen P, Faverly D. MR findings of a primary intramedullary malignant melanoma: Case report and literature review. AJNR Am J Neuroradiol 2001;22:1864-6.

7. Yamasaki T, Kikuchi H, Yamashita J, Asato R, Fujita M. Primary spinal intramedullary malignant melanoma: case report. Neurosurgery 1989;25:117-21.

8. Larson TC 3rd, Houser OW, Onofrio BM, Piegras DG. Primary spinal melanoma. J Neurosurg 1987;66:47-9.

9. Cetinalp NE, Yildirim AE, Divanlioglu D, Belen D. An uncommon intramedullary tumor: primary spinal cord melanoma. Asian Spine J 2014;8:512-5

10. Jeong DH, Lee CK, You NK, Kim SH, Cho KH. Primary spinal cord melanoma in thoracic spine with leptomeningeal dissemination and presenting hydrocephalus. Brain Tumor Res Treat 2013;1:116-20. 